\title{
Role of Different Pain Killers in Control of Diabetic Neuropathy Pain-A Review
}

\author{
Keron Akintola Ayodele Blair ${ }^{1}$, Ibrahim Khalil ${ }^{2}$, Muhammad Muneeb Arshad ${ }^{3}$, Oluwasegun \\ Shoewu ${ }^{4}$, Mahnoor Aitzaz Khan ${ }^{5}$, Fatima Saqib Rashid ${ }^{6}$, Muhammad Zarak Sarwar ${ }^{7}$, Muhammad \\ Suhaib $^{8}$, Muhammad Jahanzaib Khan', Abdullahi Abubakar Sadiq ${ }^{10}$, Tetiana Medvid ${ }^{12}$, \\ Muhammad Sikandar Karim ${ }^{11}$ and Nadeem Iqbal ${ }^{13 *}$
}

${ }^{1}$ American International School of Medicine, Georgetown Guyana

${ }^{2}$ Shifa College of Medicine, Pakistan

${ }^{3}$ Shifa College of medicine, Pakistan

${ }^{4}$ Olabisi Onabanjo College of Health Sciences, Ogun State University

${ }^{5}$ Shifa College of Medicine, Pakistan

${ }^{6}$ Shifa College of Medicine, Pakistan

${ }^{7}$ Shifa College of Medicine

${ }^{8}$ Diana, princess of Wales Hospital, Grimsby, UK

${ }^{9}$ Shifa College of Medicine

${ }^{10}$ I.Ya.Horbachevsky Ternopil State Medical University, Ukraine

${ }^{11}$ King Edward Medical University, Pakistan

${ }^{12}$ Danylo Halytsky Lviv, National Medical University,Ukraine

${ }^{13}$ PKLI, Lahore, Pakistan

*Corresponding author: Nadeem Iqbal, Dept of Urology and Kidney Transplant, Pakistan Kidney and Liver Institute Lahore, Pakistan

\section{ARTICLE INFO}

Received: 幽 September 17, 2021

Published: 曲 September 24, 2021

Citation: Keron Akintola Ayodele Blair, Shifa College of Medicine, Muhammad Muneeb Arshad, Mahnoor Aitzaz Khan, Nadeem Iqbal, et al., Role of Different Pain Killers in Control of Diabetic Neuropathy Pain-A Review. Biomed J Sci \& Tech Res 39(1)-2021. BJSTR. MS.ID.006234.
ABSTRACT

Diabetic neuropathy [DN] is a continual complication of diabetes mellitus (DM). It has an approximate pervasiveness ranging from thirty to fifty percent in subjects suffering from this disease, depending on the technique utilized for diagnosis. Additionally, DM has remained the top causative factor of polyneuropathy in the modern world. As much as fifty percent of the polyneuropathies are related to DM. It is more common in chronic DM: it negatively impacts the quality of life (QOL) in those suffering from it. Polyneuropathies cause chronic neuropathic pain, resulting in depression, anxiety, and insomnia among sufferers. Diabetic neuropathy is a painful and disabling condition that has enormous incurring costs in terms of disrupted quality of life and financial implication while treating its complications. Various pain killers have been tried in this regard with varying results. Aim of this review was to delve into various drugs outcomes in this regard.

Keywords: Painful Diabetic Neuropathy; Pain Control; Painkillers; Chronic Pain; Management

\section{Introduction}

Diabetic neuropathy (DN) is a frequent complication of diabetes mellitus (DM). It has an approximate prevalence ranging from thirty to fifty percent in subjects suffering from this disease, depending on the technique utilized for diagnosis [1]. Additionally, DM has remained the top causative factor of polyneuropathy in the modern world. As much as fifty percent of the polyneuropathies are related to DM [2]. It is more common in chronic DM: it negatively impacts the quality of life (QOL) in those suffering from it. Polyneuropathies 
cause chronic neuropathic pain, resulting in depression, anxiety, and insomnia among sufferers [1,2]. Diabetic polyneuropathy is defined as "phenomenon of symmetrical, distal and progressive degeneration of the sensorimotor and autonomic peripheral fibers, due to metabolic and microvascular changes in as a result of chronic hyperglycemia (DM) and other cardiovascular risk factors" [1]. More than four hundred million people are suffering from diabetes mellitus globally (3). Out of them, up to one-quarter fall prey to chronic painful diabetic neuropathy (PDN). Wherein they present with symptoms of neuropathic pain, continuous or intermittent more than three months [2,4]. Generally, the pain starts distally, is remarkably unpleasant at night, and follows a proximal and symmetrical progression: discomfort initially starts the toes, feet, then follows ankles. Patients' description of this pain is a "burning" sensation accompanying by a feeling of tingling. Uncommonly, it may manifest as allodynia (sensitive to touch such as combing hair), wherein normal activities lead to pain [4-6]. Hitherto, its diagnosis and treatment are a troublesome task. It is challenging and is still a debatable issue. It is of note here that up to more than one-third of subjects who have PDN did not receive a suitable treatment strategy for their pain, while every eight patients did not even go to a doctor for seeking help in this regard [4]. The effectiveness of different regimens for this disease has shown mixed results. More work is required in this regard.

\section{Methods}

We did search on PubMed, Medline database publications using: Painful diabetic neuropathy, Pain control, painkillers, chronic pain, Management. The publications included were special communications, reviews, conferences papers, books, and research studies regarding the subject matter over last twenty-five years.

\section{Discussion}

Diabetic neuropathy is a painful and disabling ailment that has enormous incurring costs in terms of disrupted quality of life and financial implication while treating its complications. Its incidence is increasing gradually as a sequel of imperfect treatment compliance and so imprecise glycemic control [6-12]. Its prevalence is unalike in different parts of the world ascribable to the heterogeneity of population and differences in healthcare systems, financial restraints, and social cognizance. Gabapentin monotherapy has established itself to be effectual and nicely tolerated when used for the care of pain and sleep disturbance in patients with diabetic polyneuropathy (DPN). Various studies have supported the role of gabapentin in this regard. In one RCT, gabapentin and amitriptyline were compared as monotherapies and deduced that both were equally efficacious in pain control in diabetic PN [13]. While another study showed that neither gabapentin nor nortriptyline was more effective as monotherapy when compared to combination therapy of both [14]. Pregabalin has been frequently studied as a monotherapy for the management of painful Polyneuropathy $[15,16]$. A study compared the effects of pregabalin and amitriptyline in patients with painful DPN, and both therapies were found safe and efficacious as monotherapies [17]. It is noteworthy that side effects were observed less frequently in pregabalin-treated Subjects. Holbech et al. demonstrated the superiority of pregabalin as monotherapy when compared to placebo [18]. Gonzalez-Duarte et al. too found promising results. Regarding the potential role of pregabalin as monotherapy in prediabetic small-fiber neuropathic pain, when compared to placebo [19].

Other anticonvulsants drugs such as topiramate provided pain control in a better way as compared to the placebo in patients who had moderate intensity of diabetic neuropathic pain [32]. Lacosamide is another safe drug that can be effective monotherapy for the treatment of DPN either as a monotherapy or as an add-on $[21,22]$. The role of Lamotrigine, as monotherapy, has not been much of a success in the management of painful DPN $(23,24)$. Evidence regarding utilization of sodium valproate or oxcarbazepine in the management of Polyneuropatic pain is also not clear [25,26]. Oxcarbazepine, Levetiracetam, perampanel, and other experimental anticonvulsants, such as ABT-639 and PF-05089771, did not show much of a value in the treatment of Polyneuropathic pain $[27,28]$.

Antidepressants such as Serotonin-Norepinephrine Reuptake Inhibitors, Tricyclic, and Tetracyclic Antidepressants Tricyclic (TCAs), and tetracyclic antidepressants (TeCAs) have also been tried in this regard. In one RCT [29], venlafaxine manifested its effectuality in controlling painful Diabetic Polyneuropathy pain at high doses as compared to low doses (150-225 mg daily vs $75 \mathrm{mg}$ daily). In yet another study venlafaxine was found to be inferior to pregabalin in this regard [30]. Duloxetine monotherapy was found to be an equally potent agent as gabapentin for the treatment of Diabetic Polyneuropathy pain, however with much better tolerability [31]. Likewise, duloxetine showed efficacy comparable to pregabalin for the treatment of such pain [32]. Tricyclic and Tetracyclic Antidepressants Tricyclic (TCAs) and tetracyclic antidepressants (TeCAs) have shown mixed results in studies relating to the management of painful DPN [33]. Opioids such as tramadol are efficacious as monotherapy or in combination therapy with paracetamol or acetaminophen in ameliorating poly neuropathic pain [34]. The beneficial effects of oxycodone/naloxone have not been much confirmed. In a study, dextromethorphan/quinidine as monotherapy resulted in amelioration of pain due to DPN [35]. Topical application of Capsaicin has been utilized either in form of a patch or a lotion in varying strengths. Studies have depicted the effectuality of topical application of capsaicin in pain reduction due to diabetic neuropathy. On the other hand, few studies were of the view that capsaicin lotion did not attain a statistically significant 
pain control in patients having Diabetic neuropathy [36]. Utilization of glyceryl-trinitrate spray [37] and isosorbide dinitrate spray has shown a statistically significant, but momentary, pain-relieving effect and amelioration in the burning sensation when used in subjects who from painful Diabetic neuropathy pain. Ketamine/ amitriptyline cream and Topical clonidine as add-on drugs, did not attain significant amelioration of pain [38]. Utilization of Botulinum Toxin Type A as intradermal injection (on dorsum of foot) resulted in attaining adequate pain control, when used in subjects with diabetic neuropathy pain $[39,40]$. Few other therapies without strong evidence include use of herbal therapies such as topical application of nutmeg extract oil in controlling of pain due to diabetic neuropathy pain. Great caution must be observed when prescribing chronic guideline medications since they may cause significant side effects in patients with pre-existing disease. These side-effects may vary depending on the drug prescribed such as pregabalin which should not be used in patients with cardiac failure (risk of decompensated cardiac failure), tramadol may lower the seizure threshold in patients with epilepsy, amitriptyline should not be used in patients with cardiovascular disease (worsens disease and increases risk of torsade's de pointes), and glaucoma. Patients being treated for diabetic neuropathy should be reevaluated every six weeks when on treatment and tapering of their therapy with eventual end to prevent adverse effects [41].

\section{Conclusion}

Various pharmacological agents are effective in treating diabetic polyneuropathy pain. There has been a moderate decrease in pain after using these drugs. More RCTs are required to explore safer and optimum options in this regard.

\section{References}

1. Hoffman EM, Staff NP, Robb JM, St Sauver JL, Dyck PJ, Klein CJ (2015) Impairments and comorbidities of polyneuropathy revealed by population-based analyses. Neurology 84(16): 1644-1651.

2. Abbott CA, Malik RA, van Ross ER, Kulkarni J, Boulton AJ (2011) Prevalence and characteristics of painful diabetic neuropathy in a large community-based diabetic population in the U.K. Diabetes Care 34(10): 2220-2224.

3. Finnerup NB, Attal N, Haroutounian S, McNicol E, Baron R, Dworkin RH, et al. (2015) Pharmacotherapy for neuropathic pain in adults: a systematic review and meta-analysis. Lancet Neurol 14(2): 162-173.

4. Bouhassira D, Letanoux M, Hartemann A (2013) Chronic pain with neuropathic characteristics in diabetic patients: a French cross-sectional study. PLoS One 8(9): e74195.

5. Spallone V, Lacerenza M, Rossi A, Sicuteri R, Marchettini P (2012) Painful diabetic polyneuropathy: approach to diagnosis and management. Clin J Pain 28(8): 726-743.

6. Jain R, Jain S, Raison CL, Maletic V (2011) Painful diabetic neuropathy is more than pain alone: examining the role of anxiety and depression as mediators and complicators. Curr Diab Rep Aug;11(4): 275-284.

7. Abdissa D, Hamba N, Kene K, Bedane DA, Etana G, Muleta D, Gerbi A (2020) Prevalence and Determinants of Peripheral Neuropathy among
Type 2 Adult Diabetes Patients Attending Jimma University Medical Center, Southwest Ethiopia, 2019, an Institutional-Based Cross-Sectional Study. J Diabetes Res 2020: 9562920.

8. Hayes A, Arima H, Woodward M, Chalmers J, Poulter N, Hamet P, Clarke P (2016) Changes in Quality of Life Associated with Complications of Diabetes: Results from the ADVANCE Study. Value Health 19(1): 36-41.

9. Bekele M, Norheim OF, Hailu A (2021) Cost-Effectiveness of Saxagliptin Compared with Glibenclamide as a Second-Line Therapy Added to Metformin for Type 2 Diabetes Mellitus in Ethiopia. MDM Policy Pract 6(1): 23814683211005771.

10. Kwon CS, Seoane-Vazquez E, Rodriguez-Monguio R (2018) Cost-effectiveness analysis of metformin+dipeptidyl peptidase-4 inhibitors compared to metformin+sulfonylureas for treatment of type 2 diabetes. BMC Health Serv Res 18(1): 78.

11. Torre E, Bruno GM, Di Matteo S, Martinotti C, Valentino MC, Bottaro LC, Colombo GL (2020) Cost-Utility Analysis of Saxagliptin/Dapagliflozin Versus Gliclazide and Insulin Glargine: Economic Implications of the Outcomes of the CVD-Real Studies I and II. Health Serv Insights 13: 1178632920929982

12. Kuo S, Ye W, de Groot M, Saha C, Shubrook JH, Hornsby WG Jr, et al. (2021) Cost-effectiveness of Community-Based Depression Interventions for Rural and Urban Adults with Type 2 Diabetes: Projections from Program ACTIVE (Adults Coming Together to Increase Vital Exercise) II. Diabetes Care 44(4): 874-882.

13. Morello CM, Leckband SG, Stoner CP, Moorhouse DF, Sahagian GA (1999) Randomized double-blind study comparing the efficacy of gabapentin with amitriptyline on diabetic peripheral neuropathy pain. Arch Intern Med 159(16): 1931-1937.

14. Gilron I, Bailey JM, Tu D, Holden RR, Jackson AC, Houlden RL (2009) Nortriptyline and gabapentin, alone and in combination for neuropathic pain: a doubleblind, randomised controlled crossover trial Lancet 374(9697): 1252-1261.

15. Arezzo JC, Rosenstock J, LaMoreaux L, Pauer L (2008) Efficacy, and safety of pregabalin $600 \mathrm{mg} / \mathrm{d}$ for treating painful diabetic peripheral neuropathy: a double-blind placebo-controlled trial. BMC Neurol 8: 33.

16. Satoh J, Yagihashi S, Baba M (2011) Efficacy and safety of pregabalin for treating neuropathic pain associated with diabetic peripheral neuropathy: a 14 week, randomized, double-blind, placebo-controlled trial. Diabet Med 28(1): 109-116

17. Bansal D, Bhansali A, Hota D, Chakrabarti A, Dutta P (2009) Amitriptyline vs. pregabalin in painful diabetic neuropathy: a randomized double blind clinical trial. Diabet Med 26(10): 1019-1026.

18. Holbech JV, Bach FW, Finnerup NB, Brøsen K, Jensen S, Sindrup SH (2015) Imipramine and pregabalin combination for painful polyneuropathy: a randomized controlled trial. Pain 156(5): 958-966.

19. Gonzalez-Duarte A, Lem M, Di'az-Di'az E, Castillo C, Ca'rdenas-Soto K (2016) The efficacy of pregabalin in the treatment of prediabetic neuropathic pain. Clin J Pain 32(11): 927-932.

20. Raskin P, Donofrio PD, Rosenthal NR (2004) Topiramate vs placebo in painful diabetic neuropathy: analgesic and metabolic effects. Neurology 63(5): 865-873.

21. Rauck RL, Shaibani A, Biton V, Simpson J, Koch B (2007) Lacosamide in painful diabetic peripheral neuropathy: a phase 2 double-blind placebo-controlled study Clin J Pain 23(2): 150-158.

22. Ziegler D, Hidvegi T, Gurieva I (2010) Efficacy and safety of lacosamide in painful diabetic neuropathy. Diabetes Care 33(4): 839-841.

23. Eisenberg E, Lurie Y, Braker C, Daoud D, Ishay A (2001) Lamotrigine reduces painful diabetic neuropathy: a randomized, controlled study. Neurology 57(3): 505-509. 
24. Jose VM, Bhansali A, Hota D, Pandhi P (2007) Randomized double-blind study comparing the efficacy and safety of lamotrigine and amitriptyline in painful diabetic neuropathy. Diabet Med 24(4): 377-383.

25. Otto M, Bach FW, Jensen TS, Sindrup SH (2004) Valproic acid has no effect on pain in polyneuropathy: a randomized, controlled trial. Neurology 62(2): 285-288.

26. Beydoun A, Shaibani A, Hopwood M, Wan Y (2006) Oxcarbazepine in painful diabetic neuropathy: results of a dose-ranging study. Acta Neurol Scand 113(6): 395-404.

27. Ziegler D, Duan WR, And G, Thomas JW, Nothaft W (2015) A randomized double-blind, placebo-, and activecontrolled study of T-type calcium channel blocker ABT-639 in patients with diabetic peripheral neuropathic pain. Pain 156(10): 2013-2020.

28. McDonnell A, Collins S, Ali Z (2018) Efficacy of the Nav1.7 blocker PF05089771 in a randomised, placebo-controlled, double-blind clinical study in subjects with painful diabetic peripheral neuropathy Pain. 159(8): 1465-1476.

29. Rowbotham MC, Veeraindar G, Kunz NR, Lei D (2004) Venlafaxine extended release in the treatment of painful diabetic neuropathy: a double-blind, placebo-controlled study. Pain 110(3): 697-706.

30. Razazian N, Baziyar M, Moradian N, Afshari D, Bostani A (2014) Mahmoodi M. Evaluation of the efficacy and safety of pregabalin, venlafaxine, and carbamazepine in patients with painful diabetic peripheral neuropathy. A randomized, double-blind trial. Neurosciences 19(3): 192-198.

31. Majdinasab N, Kaveyani H, Azizi M (2019) A comparative double-blind randomized study on the effectiveness of duloxetine and gabapentin on painful diabetic peripheral polyneuropathy. Drug Des Dev Ther.17, 13: 1985-1992.

32. Tesfaye S, Wilhelm S, Lledo A (2013) Duloxetine and pregabalin: highdose monotherapy or their combination? The "COMBO-DN Study"-a multinational, randomized, double-blind, parallel-group study in patients with diabetic peripheral neuropathic pain Pain 154(12): 26162625 .

ISSN: 2574-1241

DOI: 10.26717/BJSTR.2021.39.006234

Nadeem Iqbal. Biomed J Sci \& Tech Res

(C) (P) This work is licensed under Creative Commons Attribution 4.0 License

Submission Link: https://biomedres.us/submit-manuscript.php
33. Dinat N, Marinda E, Moch S, Rice ASC, Kamerman PR (2015) Randomized, double-blind, crossover trial of amitriptyline for analgesia in painful HIV-associated sensory neuropathy. PLoS ONE 10(5): e0126297.

34. Freeman R, Raskin P, Hewitt DJ (2007) Randomized study of tramadol/ acetaminophen versus placebo in painful diabetic peripheral neuropathy. Curr Med Res Opin 23(1): 147-161.

35. Shaibani AI, Pope LE, Thisted R, Hepner A (2012) Efficacy, and safety of dextromethorphan/quinidine at two dosage levels for diabetic neuropathic pain: a double-blind, placebo-controlled, multicenter study. Pain Med.13(2): 243-254.

36. Kulkantrakorn K, Chomjit A, Sithinamsuwan P, Tharavanij T, Suwankanoknark J, Napunnaphat P (2019) 0.075\% Capsaicin lotion for the treatment of painful diabetic neuropathy: a randomized, doubleblind, crossover, placebo-controlled trial. J Clin Neurosci 62: 174-179.

37. Agrawal RP, Choudhary R, Sharma P (2007) Glyceryl trinitrate spray in the management of painful diabetic neuropathy: a randomized double-blind placebo controlled cross-over study. Diabetes Res Clin Pract. 77(2): 161-167.

38. Cambell CM, Kipnes MS, Stouch BC (2012) Randomized control trial of topical clonidine for treatment of painful diabetic neuropathy. Pain 153(9): 1815-1823.

39. Yuan RY, Sheu JJ, Yu JM, (2009) Botulinum toxin for diabetic neuropathic pain: a randomized doubleblind crossover trial. Neurology 72(17): 1473-1478.

40. Motilal S, Maharaj RG (2013) Nutmeg extracts for painful diabetic neuropathy: a randomized, double-blind, controlled study. J Altern Complement Med 19(4): 347-352.

41. Aisha Hasan, Khilan MH, Khan A, Hassan MH, Taseer AR, et al. (2020) Comparison of Gabapentin Monotherapy vs. Combination Therapy of Methyl Cobalamin and Gabapentin in Treating Diabetic Neuropathic Pain. J Biol Today's World 9(9): 001-003.

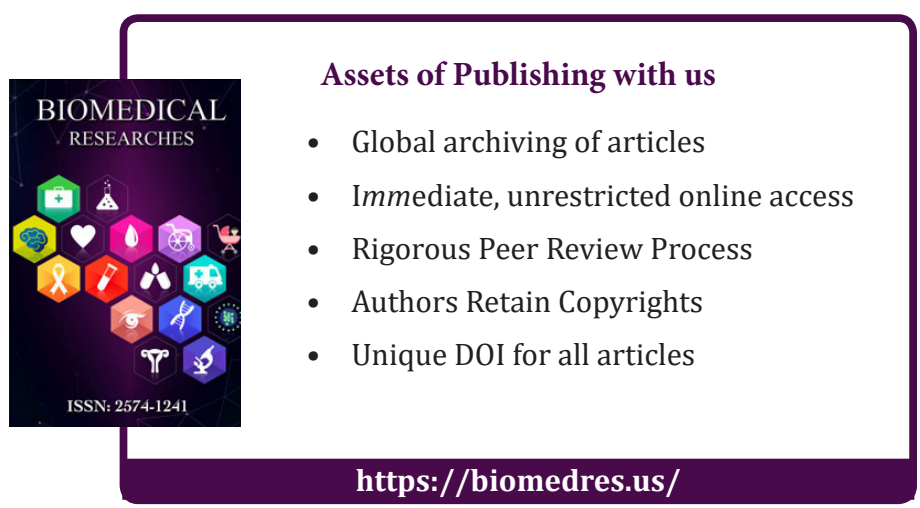

